\begin{tabular}{c} 
Volume and Issues Obtainable at Center for Sustainability Research and Consultancy \\
Journal of Business and Social Review in Emerging Economies \\
ISSN: 2519-089X (E): 2519-0326 \\
Volume 6: No. 1, March 2020 \\
CSRᄃ \\
Journal homepage: www.publishing.globalcsrc.org/jbsee \\
\hline
\end{tabular}

\title{
Declining Employee Engagement \& Employee Performance: The Noxious Effects of Workplace Bullying
}

\author{
${ }^{1}$ Muhammad Shaukat Malik, ${ }^{2}$ Shahzadi Sattar \\ ${ }^{1}$ Dean Faculty of Law, Commerce \& Business Administration Bahauddin Zakariya University Multan, \\ Pakistan shoukatmalik@bzu.edu.pk \\ ${ }^{2} \mathrm{PhD}$ Scholar Institute of Banking \& Finance Bahauddin Zakariya University, / Lecturer NFC IET \\ Multan, Pakistan: shahzadi.sattar@nfciet.edu.pk
}

\begin{tabular}{l}
\multicolumn{1}{c}{ ARTICLE DETAILS } \\
\hline History \\
Revised format: February 2020 \\
Available Online: March 2020 \\
Keywords \\
Workplace Bullying, Emotional \\
Exhaustion, Employee \\
Performance and \\
Employee Engagement
\end{tabular}

JEL Classification:

J59

\section{ABSTRACT}

The rationale of this research study is to inspect about variations in employee performance and employee engagement in Pakistani context brought about by the workplace bullying. Another objective is to produce comprehensive empirical evidence of bullying in the specific Pakistani context. The purpose of paper is to examine whether emotional exhaustion plays a mediating role between workplace bullying, employee performance and employee engagement. Even most of the organizations are unaware about this critical issue to curtail down its effect.

A cross-sectional design is used in the research study, which focuses on emotional exhaustion that serves as a mediator between workplace bullying and employee performance and employee engagement. The paper is based upon cross-sectional and selfreported survey research design. Furthermore longitudinal research design is recommended for future investigation of the relationships among these constructs. Consolidated policies must be sought by the management to combat with the vicious prevalence of workplace bullying. This will not only encourage the conducive work environment but also ensure positive work climate among employees.

(C) 2020 The authors, under a Creative Commons Attribution-

NonCommercial 4.0

Corresponding author's email address: shahzadi.sattar@nfciet.edu.pk

Recommended citation: Malik, M. S. \& Sattar, S., (2020). Declining Employee Engagement \& Employee Performance:The Noxious Effects of Workplace Bullying. Journal of Business and Social Review in Emerging Economies, 6(1), 165-176

DOI: $10.26710 /$ jbsee.v6i1.1035

\section{Introduction}

Workplace bullying is a disguised widespread epidemic disease victimizing the children, adults and mature people at the workplace (Gupta et al. 2017; Giorgi 2012; Nielsen and Einarsen 2012). Still its deleterious effects are not realized in the developing countries organizations particularly like Pakistan. In broader terms, bullying is the behavior to intimidate, undermine and frightening people psychologically, emotionally and physically (Einarsen et al. 2011). This behavior is manifested in humiliating colleagues, taking credit of someone else work and excessively legitimizing authority over span of control. 
Unfortunately, this issue is not given so much attention as it deserves to be addressed at the workplace (Gupta et al. 2017, D'Cruz 2016). Contemporary work life is much affected by this toxic phenomenon (Hurley et al. 2016). According to Einarsen et al , (2011) the term workplace bullying is coined by the Adams in 1992 which typically refers to the harassment behavior which is prolonged and consistent in practice assuming power deficit in victims and escalating it to more aggressive attitude. Workplace bullying is a new beast in the kingdom of organizational behavior attracting much attention now days (Attell et al. 2017; Rockett et al. 2017). This study focuses on the Pakistani workplace context for certain reasons firstly workplace bullying in developing countries is still in its infancy as reported by Gupta et al. (2017) \& D'Cruz (2016). Therefore, the insight into workplace bulling through rigorous research will be substantial to dig out the menace of bullying. This research is an endeavor to emphasize on reporting of bullying which is largely overlooked and unaddressed. If it is addressed and curtailed down, the organizations in Pakistan will have to bear less turnover costs. Another predominant issue is the lack of consolidated laws that besides the widespread prevalence of workplace bullying remain weak. One of the major reasons to accept the workplace harassment is the national culture (Arenas et al. 2015a; Escartin et al. 2011) which gives empirical evidence of inverse relationship of workplace intimidating and its consequences. (Park and Ono 2016; Vie et al. 2011).

\section{Literature Review}

\subsection{Workplace Bullying and Employee Performance}

According to Devonish (2013), undoubtedly workplace bullying has repercussions. The repercussions may be categorized as the detrimental effects or diverse consequences for the employees. It is considered to be the one of the most important emerging issue that has attracted a great concern of HR and business managers. Since the aftermaths involve employee performance and the outcomes. In order to determine the efficiency and effectiveness of organizations employee performance is one of the important yardsticks. There are certain threats for both management and workers in the organizations and workplace bullying are significant among them because it hurts all those employees who want to ensure performance at its peak to maximize profits and to secure competitiveness.

Devonish (2013) also verifies the fact that the study of workplace bullying has emerged substantially as a research area and is drawing scholarly attention. Theories and models pertaining to job stress have heavily influenced the wide variety of perspectives on the nature of relationships between workplace bullying and employee performance. The prior studies like as conducted by the Jackson et al., (2002) \& McMillan, (1995) have fundamentally exposed and exposed that exposure to workplace bullying is connected with weakened or damaged job performance. However, another Meta analysis as conducted by the Bowling and Beehr, (2006) reveals that albeit weakly but higher levels of workplace harassment (A synonym that is used frequently for the workplace bullying) yields to lower levels of job performance. No doubt, there is not an ample amount of research conducted on this perspective.

Even though there is a lack of vast variety of researches on workplace bullying and employee performance relationships but a smaller body of researches supports that workplace bullying has the direct and indirect sway via psychological distress mechanisms.

\section{Hypothesis 1: \\ There is a significant negative relationship between workplace bullying and} employee performance

\subsection{Workplace Bullying, Emotional Exhaustion and Employee Performance}

Weiss and Cropanzano in1996 developed the affective event theory. The work environments in the organizations like the characteristics of jobs, Job demands and work events like daily hassles and uplifts literally affect the emotional reactions of the employees, which in return affects Job Performance and Job Satisfaction. According to this theory, the emotional exhaustion or emotional wear and tear is the result of the unwelcoming events like workplace bullying and sexual harassment. The work events produce psychological reactions in employees. Miner et al. (2005) collected various evidences compatible with the affective event theory. The daily work events that are encountered by the employees affect their emotional and when it happens like this their behaviors get affected. Since workplace, bullying is a long term, 
unrelenting negative behavior that is demonstrated by the perpetrator on the victims therefore it is considered as the unconstructive job event. Nielsen \& Einarsen, (2012) is of the view that this cruel event may generate tensions, anxiety, depression, fear symptoms of stress among the victims of bullying (Peng, YC.et al 2016).

Hobfall \& Shirom, (2001) are of the view that by believing in Conservation of resources theory (COR) THEORY as a stress theory which states that there is always a motivation in human beings that drives them to maintain their current as well as future resources. Here the psychological stress occurs in three states: when there is a constant threat of the losing the resources, no further addition in current resources , lack of replenishment of resources or when there is actual loss of resources as well. COR theory states that loss of resources drive human beings into stress. Now how it actually works in an organization the employee goes for self assessment whether he has the capability to cope up with the stress. If there is no coping up strategy the resources are constantly drained without being replenished. In stressful situations, emotional exhaustion is conspicuous negative outcome. The most important repercussion of emotional exhaustion is job burnout. According to Maslach \& Jackson, (1984); Maslach, Schaufeli, \& Leiter, (2001); Witt, Andrews, \& Carlson, (2004) employee performance and turnover is effectively predicted by the emotional exhaustion. The employees who put up with or bear with the patience the phenomenon of emotional exhaustion for extended period of time they feel emotionally num and lack energy (Hochschild 1983 and Maslach ,1982).

This suppression make the employees feel exhausted emotionally and physiologically and also adversely affects the workplaces (Wright \& Cropanzano, 1998). Another major contribution is done by Spector and Fox(2005) who developed the stressor-emotion model which emphasized on the emotions as the major response to workplace stressors. These are the emotions that contribute to job satisfaction, increased job performance and even may cause workplace deviance that may occur momentarily or impellent or it may be the immediate response. The rigorous researches depicted that emotional exhaustion aggravates the workplace deviant behavior in workers (Bolton, Harvey, Grawitch, \& Berber, 2012; Raman, Sambasivan \& Kumar, 2016). According to the Trépanier, Fernet, and Austin (2013) as the morale for the work engagement goes down the job burnout increases causing dissatisfaction and dissatisfaction directs towards the distractions like lesser employee performance.

Thus based upon the above-mentioned discussion our current research investigates the connection between workplace bullying and employee performance where emotional exhaustion is serving as a mediator.

\section{Hypothesis 2: $\quad$ Emotional Exhaustion mediates the relationship between workplace bullying and employee performance}

\subsection{Workplace Bullying and Employee Engagement}

The psychological connection of employees with their work is known to be the employee engagement .The employees with higher level of the energy are engaged employees they have more zest, enthusiasm and zeal about their work and they are highly involved and engrossed in assignments (May, Gilson, \& Harter, 2004). Prior studies done by Einarsen et al (2016), Park \& Ono, (2016), Rodriguez Munoz et al, (2009) \& Trépanier et al., (2013) depict the convergent views about the notion that workplace bullying is negatively related to employee engagement. One of the theoretical perspectives like Job demand resources model JD-R model along with conservation of resources theory has been used to explain bullying and employee engagement relationship especially by Bakker \& Demerouti, (2007) and Crawford, LePine, \& Rich, (2010).

According to Macey \& Schneider, (2008) Engagement is a broad-spectrum construct comprising of trait, state, motivation and behavioral forms that implies a mixture of discretionary effort and affective energy to organization and ones work. Kahn (1990) is the very first person who introduced the concept of work engagement in organizational psychology. His narrative is very much clear about work engagement that personal work and work roles are amalgamated together. Schaufeli et al (2002) has given the widely acceptable definition of work engagement that is "workplace engagement is a fulfilling, positive job related mind set which is characterized by dedication, vigor and absorption" where vigor refers to the mental resilience, high energy while working. It refers to the personal discretion and persistent attitude 
towards work even in hard times. Another dimension called dedication is all about the challenge, pride and inspiration, enthusiasm and a sense of significance. Another dimension is the absorption that is being fully engaged, preoccupied and riveted by work. Even if time flies quickly, the dedicated worker finds it difficult to detach himself from work. The psychological connection of an employee with his work is known as employee engagement. As per May, Gilson, \& Harter (2004) the psychologically connected employees are excited and have more levels of energy to do work and to cope up with the obstacles of work in another words they are fully immersed in their job

Park \& Ono (2016) put forward the view about the conservation of resources theory. According to this theory, energetic processes are reduced when one is victimized of bullying. Since workplace bullying results in deprivation or depletion of emotional resources. The employee engagement is also reduced due to this phenomenon as explained by the JD-R model. The affected employees suffer from prolonged mental stress. Workplace bullying in other words is a hindrance demand and if the employees feel difficulty to cope up with it, it results in low employee engagement (Einarsen et al., 2016). The basis of this research is Conservation of resource theory presented by Hobfoll (1989). In the lime light model of engagement presented by Kahn (1990) along with the COR theory the relationship between the workplace bullying and employee engagement will be explained by conducting the research.

Kahn, (1990) was of the view that employees want their psychological terms to be fulfilled at the job like safety, availability and meaningfulness. Employees must feel that they have a worth in organization, they should feel valuable, have the ability to contribute and receive psychological willingness if it is like this then a sense of safety is developed to demonstrate engagement and psychological resources are recharged and replenished to continue with the work. Based on conservation of resource theory it is assumed that whenever there is an atmosphere of workplace deterioration in the organization it sabotages the psychological resources that are fundamental for the employees to move on with their jobs. According to COR theory Hobfoll, (1989) states that fundamental human inducement is confinement and conservation of psychological resources which are consolidating personal characteristics and spirits. Being confronted with workplace bullying one gets depleted with all these precious resources and looses the dignity and status at work as well (Tuckey \& Neall, 2014). Furthermore Hobfoll, (2011) is of the view that loosing resources is more sorrowful than attaining the resources. The deprived employees are highly motivated to preserve their left over resources and fight to protect them to the extent they can (Hobfoll, 1989; Xu, Loi, \& Lam, 2015). So in order to save their resources employees are less likely to be indulged in their jobs that need exertion.

Based on this argument we propose our hypothesis that:

\section{Hypothesis 3: Workplace bullying negatively correlates with Employee Engagement}

\subsection{Workplace Bullying, Emotional Exhaustion and Employee Engagement}

Workplace bullying is workplace harassment, which involves frequent substandard acts like insulting, boycott and abusive behavior (Einarsen, 2000). The workplace bullying has serious type of repercussions for the targets caused by perpetrators. Most of the researchers believe that workplace bullying has significantly positive relationship with emotional exhaustion and job turnover intentions (Nielsen, Matthiesen, \& Einarsen, 2008; Houshmand et al., 2012; Nielsen \& Einarsen, 2012; Vie, GlasO, \& Einarsen, 2012; Trepanier, Fernet, \& Austin, 2013).

Given the repercussions of workplace bullying, previous researches have attempted to depict how bosses and subordinates combat bullying in their firms (Vie et al., 2012). For example, some studies have applied Affective Events Theory (AET) as per Weiss \& Cropanzano, (1996) and emphasized on the role of emotions and as a theoretical framework to express the underpinning mechanism between workplace harassment, bullying and its outcomes (Glaso, Vie, Holmdal, \& Einarsen, 2011). Glaso et al., (2011) is of the opinion that the victims' emotional experiences of affective negative reactions to bullying events, serve as a mediator between the workplace bullying and job satisfaction and even turn over intentions. Upon the exposure of vigilant workplace intimidation, the victim develops affective reactions, which are reflected in different employee outcomes. 
Even though the Affective Event theory not only incorporates and highlights the function of affective processes in forming out the experiences but still it is believed that bullying is a vicious kind of series of events that can trigger and stimulate the cognitive reactions, which are particularly reconsidering the safety conditions in the work places. Apart from the affective processes workplace intimidation, suppression and belittling produces negative impact through a thorough rational process. Still according to the Parzefall \& Salin (2010), Penhaligon, Louis, Restubog, (2013),Trepanier et al.,(2013) there are more psychological impressions and sufferings during the exposure to bullying and most of them are still not known.

The victims of workplace bullying usually develop the sense of decreased or low job morale due to the wear and tear of the emotions rather they are sabotaged by the perpetrators to feel and live with low selfefficacy. Most of the negative attitudes that are developed are workplace deviance low working performance less job engagements, developing turnover intentions and less concentration. On the other hand, retaliations from victims is again the major drawback (Rodriguez-Munoz, Baillien, De Witte, Moreno-Jimenez, \& Pastor, 2009; Trepanier et al., 2013). Employee Engagements refers to the work related state of mind which is positive one ,fulfilling and instilled with escalation of commitment.The main dimensions of employee engagement are dedication, vigor and absorption (Schaufeli \& Bakker, 2003). Employees with high job engagement tend to be associated with their assignments at work they have task identification and are more energetic to attain the goals with leaving no stone unturned (Bakker, Schaufeli, Leiter, \& Taris, 2008).

Workplace bullying is the fundamental reason of job distraction or workplace deviance, which can be observed in declining job performance and declining employee engagement as well. The decreasing employee engagement is due to the emotional deterioration and reaching to the emotional threshold level where further tolerance of violence and belittling may cause other physical and psychological diseases. Lack of involvement, vigor, dedication and absorption are the salient antecedents of decreased employee engagement. The bullying kind of the phenomenon is the mistreatments at workplace, which really could wear the targets and lessen their engagements at work (Rodriguez-Munoz et al, 2009). Based upon the previous studies and empirical evidences workplace bullying has the negative relationship with the employee engagement.

The theoretical rationale behind the preceding empirical studies is of the Conservation of Resources Theory commonly known as COR theory. The theory highlights the availability of resources based on that an employee can feel at ease, provided with lesser or scarce resources which can never be replenished an employee losses the courage to confront the worst repercussions of bullying. The employees with less emotional stability usually surrender earlier as compared to those who have greater amount of the resources since they are less vulnerable to stressors and less volatile to hostility. The available resources may be referred to as the entities, which people value such as objects e.g computers, technical equipments; others are conditions like social support and supervisor's moral support. Apart from them are the personal characteristics are also the resources like self-efficacy and intuitions and knowledge with physical energy (Hobfoll \& Shirom, 2001).

The theory of Conservation of Resources is prominent in the literature in suggesting that employees eagerly strive to retain, obtain and save their resources. The literature abounds that individuals make additional investments in physical, intellectual and technical resources so as not to be deprived of further loss of resources. The centrality of this issue is based on the view point of Gorgievski \& Hobfoll, (2008). If the stressful conditions linger on to the chronic stage the overall resources of the employees will be depleted Hobfoll \& Shirom, (2001). Gorgievski and Hobfoll (2008) propound the view that employee engagement is the real or anticipated resource gain through the energetic resources. Therefore, in the absence of resources either they are physical emotional technical or intellectual the energetic resources may suffer like less employee engagement or intense burnout affecting well-being of the victim.

The consensus view through Mikkelsen \& Einarsen, (2002), Nielsen \& Einarsen, (2012), Vie et al., (2012) confirm about the fact that bullying causes psychological health complaints, depressions. Rodriguez-Munoz, Moreno- Jimenez, Sanz Vergel, \& Garrosa Hernandez, (2010) are even of the opinion that victims may develop disorder of posttraumatic stress over a period of time.At the same time the studies done by the Hogh, Hansen, Mikkelsen, and Persson (2012) validate that exposure to bullying is 
associated with the psychological reactions to stress and strain. The reactions may be like physiological arousal upon reminders and hyper vigilance. The physiological responses like increased cortisol concentration, increased blood pressure and palpitation along with cardiac arrest due to depression may be the results of bullying.

Cognitive Activation Theory of Stress presented by Ursin \& Erickson, (2004) further confirms about bullying -health relationship phenomenon. The non-dissenters emphasize that targets subjectively conceive a situation in which they are victimized. All the stressors or stressful stimuli begin with the cognitive process of the situation. This process gets aggravated or varies in responses depending upon the increase or decrease of cognitive arousal. Whenever the targets are unable to cope up with the bullying the stress and anxiety causes them to feel down that directly affects their work engagement. Since negative situations facilitate chronic physical and cognitive activation resulting in declined work engagement Nielsen \& Einarsen, (2012). Due to direct health conditions impairment work engagements are usually on decline Meurs \& Perrewe, (2011).

Hypothesis 4: $\quad$ Emotional Exhaustion serves as the mediator between Workplace Bullying and Employee Engagement

\section{Research Design}

\subsection{Methodology}

\section{Participants and data-collection procedure}

The current research examined the mediation model of workplace bullying and employee performance, workplace bullying and employee engagement in a cross sectional sample of near about 500 employees working in various private and public sector organizations. The sectors chosen were telecommunication, banking, textile mills, FMCGs, hospitals, Petroleum firms etc. By considering the fragility of the issue like workplace bullying most of the organizations had given the tough time to researcher to dig out the primary information. In most of the cases, prior permission was sought from the concerned authorities to oblige the researcher. The selection of employees was accompanied with the criteria that at least six months time would have been passed to report bullying. Using stratified random sampling 500 employees were approached out of which 469 showed their consent to fill up the questionnaires. In the end, 367 usable questionnaires were used to analyze the data.

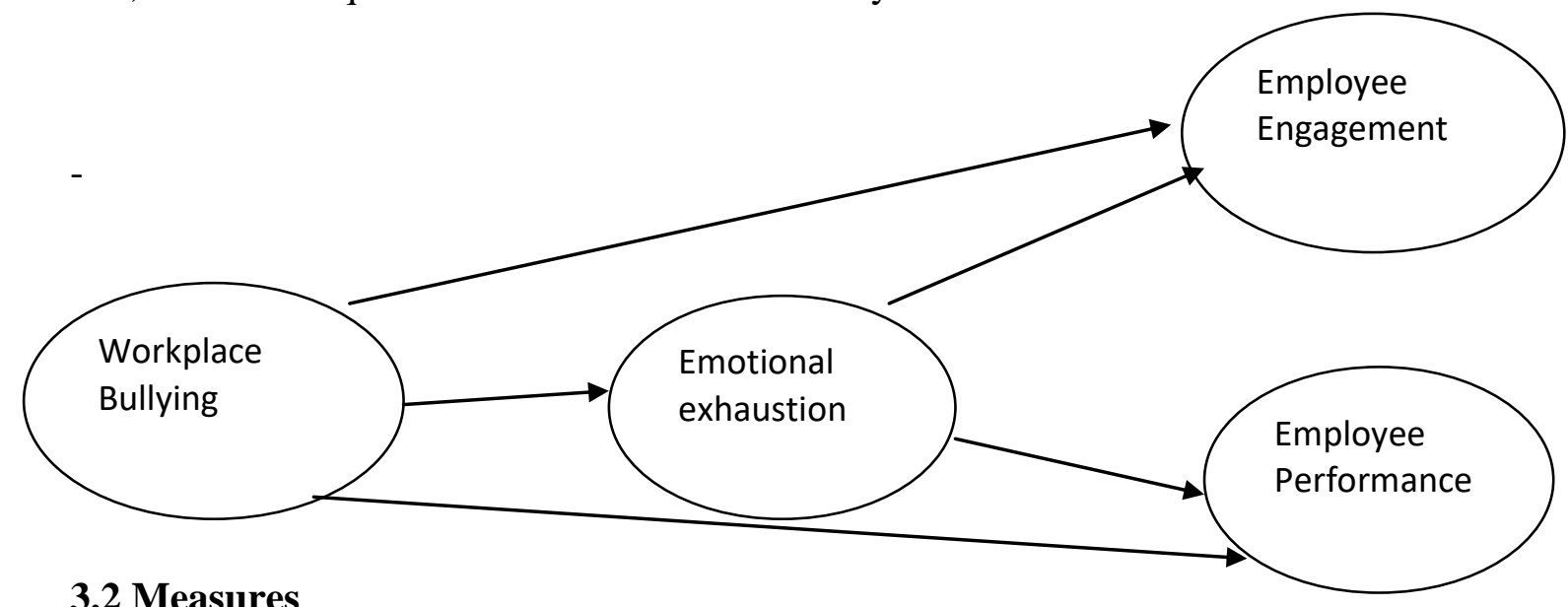

3.2 Measures

Engagement Scale: Utrecht Work Engagement Scale (UWES) validated as the 9-item scale (UWES-9) is used to measure the employee engagement worldwide. It measure the Employee engagement as the composite variable with the dimensions as vigor, dedication and absorption (Bakker et al. 2008; Salanova et al. 2005; Schaufeli et al. 2006)

Job performance: Podsakoff and MacKenzie's (1989) five-item scale items are used to measure inrole job performance while Janssen's $(2000,2001)$ nine-item are used to measure Innovative job performance in the workplace. The dimensions of in role job performance are idea generation, idea promotion and idea realization. The three items measure each dimension respectively. Most immediate high ups rate about the span of control under them for the nine innovative workplace behaviors. The 
statements are rated under five point likert scale (1, "never," to 5, "always").

Workplace bullying: NAQ-R by Hauge et al.,(2007) is a source of 23 items scale. The Negative Acts Questionnaire-Revised is used in the current study to envisage workplace bullying in targeted organizational employees (Einarsen et al., 2009).

\section{Emotional exhaustion}

Maslach Burnout Inventory is a source to measure emotional exhaustion in employees. Maslach and Jackson (1981) developed a General Survey, which comprises of five items to measure employee emotional exhaustion.

\section{Control Variables:}

This study is meant to investigate the association between workplace bullying, emotional exhaustion, employee engagement and employee performance. The demographic variables are not primarily a focus of study in this study. Therefore, to rule out any impact of these demographic variables they are controlled. In demographic parameters the age is considered as a continuous variable, gender is supposed to be a categorical variable in research and employee job tenure for the years of services is categorized as continuous variable.

\subsection{Data Analysis}

The considering data for current study were examined by using IBM SPSS Amos version 22 in order to prepare preliminary data file for data screening by using missing value analysis, normality analysis, univariate outliers, singularity and multicolinearity etc. Here, the data was analyzed for the purpose of showing the impact of workplace bullying on employees' job performance and employee engagement in the presence of mediation emotional exhaustion.

\subsection{Confirmatory Factor Analysis}

Similarly, AMOS version 22 was used to conduct Confirmatory factor analysis (CFA) to test the construct validity of the each construct (Tabachnick \& Fidell, 1996; Tabachnick \& Fidell, 2007). In literature, Brown's (2006) criteria is mostly used to identify the model fit through different model fit indices (Harrington, 2009). The absolute fit indices comprises root mean residual (RMR), and chi-square minimum difference (CMIN). Moreover, the parsimony correction indices are also used such as comparative fit indices (CFI), IFI (incremental Fit Index), TFI (Tucker Lewis Index), and root mean square error of approximation (RMSEA). The results claim adequate fit in the form of values within acceptable range such as $\mathrm{CMIN} / \mathrm{DF}=2.29 ; \mathrm{CFI}=0.93$; $\mathrm{IFI}=0.91$; $\mathrm{TFI}=\mathrm{RMSEA}=0.06$; and $\mathrm{RMR}=$ 0.04 (Kline, 2005; Hu \& Bentler, 1999; Harrington, 2009).

\section{Table I: Fit Indices of CFA}

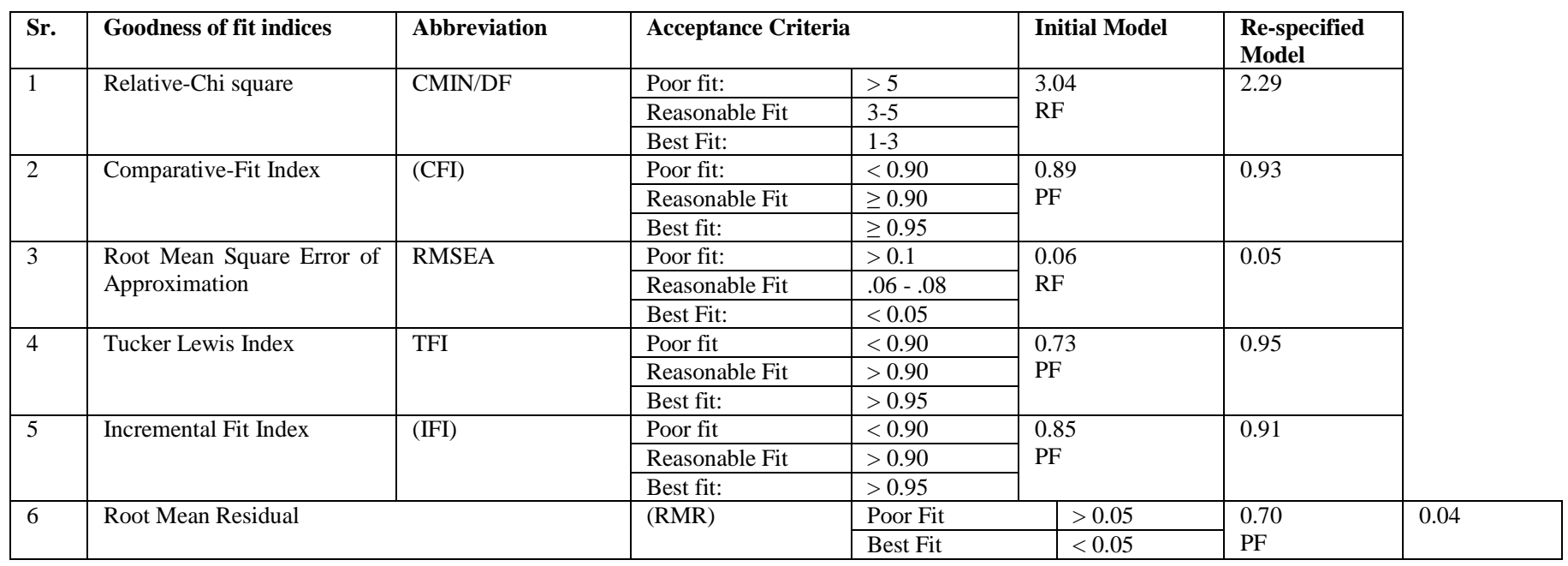




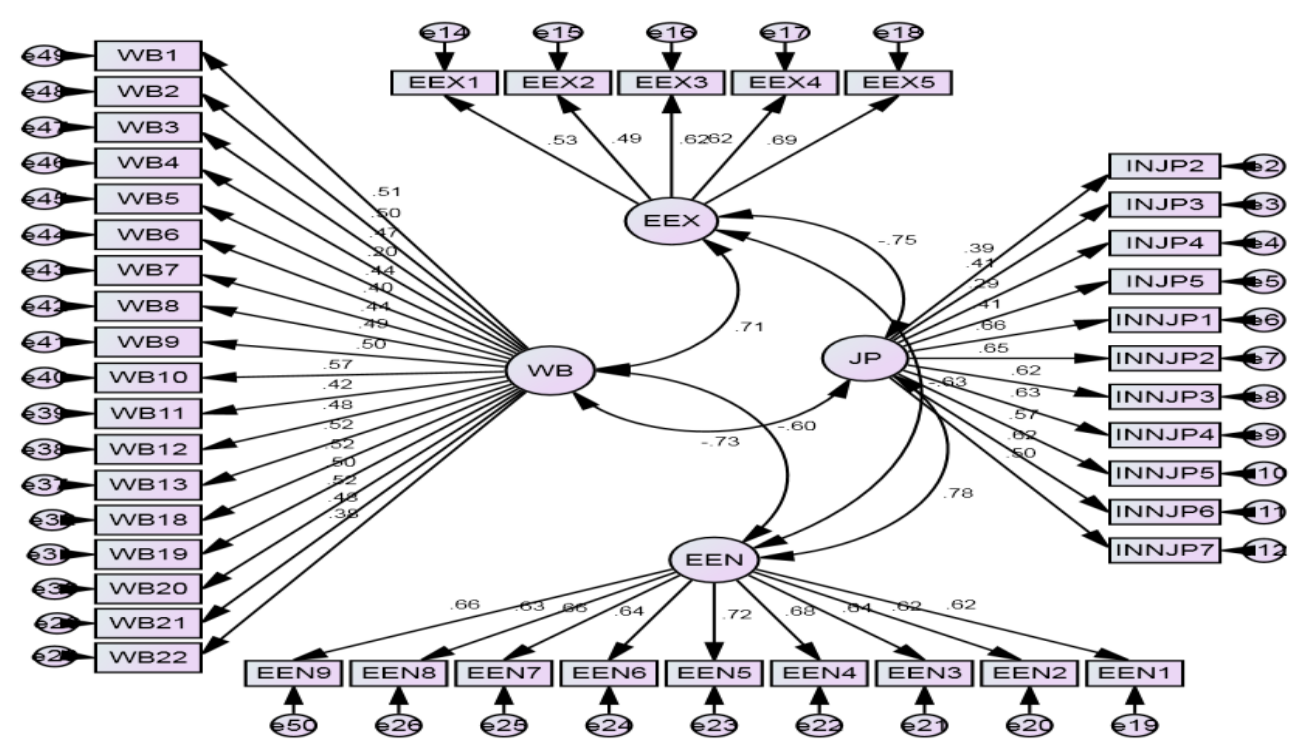

Figure I: Confirmatory Factor Analysis

Initially, model of CFA did not demonstrate adequate model fit, but after removing few items having factor loadings less than 0.40, the final model of CFA model demonstrated an adequate model fit. In addition, latent variable approach was used to test the common method variance (Bagozzi and Yi, 1990; Podsakoff et al., 2003). The significance of the structural parameters is examined both with and without the common latent methods variance factor to see whether adding it would significantly improve the model fit. Results showed that the influence of common method variance did not appear to be a major concern in this study.

Table II presents means, standard deviations and correlations of variables with eachother. The alpha coefficients for each variable are $\mathrm{JP}=0.72, \mathrm{EEN}=0.86, \mathrm{EEX}=0.79, \mathrm{WB}=0.91$ as shown in table III. Moreover, the threshold values of average variance extracted and squared correlation are also given in table III. Workplace bullying (WB) is negatively and significantly correlated with job performance (JP) as $(\mathrm{r}=-.679, p<0.01)$ and employee engagement $(\mathrm{EEN})(\mathrm{r}=-.560, p<0.01)$. In addition, workplace bullying is positively and significantly related with emotional exhaustion $(r=0.608, p<0.01)$ and emotional exhaustion is negatively and significantly correlated with job performance $(r=0.591, p<0.01)$ and employee engagement $(r=0.507, p<0.01)$. These results are consistent with our expectations based on the hypotheses outlined earlier. Hence, results claimed the acceptance of hypothesis 1 and 3.

**Correlation is significant at the 0.01 level (2-tailed)

**Correlation is significant at the 0.01 level (2-tailed)

Table III: Reliability, Average variance extracted and Squared Correlation

\begin{tabular}{lcc|cccc}
\hline Variables & & & \multicolumn{3}{c}{ Squared Correlation } \\
\hline & Reliability & AVE & WB & EEX & JP & EEN \\
\hline WB & 0.91 & 0.63 & 1 & & 1 & \\
EEX & 0.79 & 0.71 & 0.369 & 0.349 & 1 & 1 \\
JP & 0.72 & 0.69 & 0.461 & 0.358 & 0.414 & 1 \\
EEN & 0.86 & 0.75 & 0.313 & &
\end{tabular}

Table II: Mean, Standard Deviation and Correlation

\subsection{Mediation Analysis}

Following Preacher and Hayes (2004), mediation is tested by using a bootstrap method that is based on 5,000 iterations with a 95 percent confidence interval. The mediation analysis was performed to analyze the results in four steps as shown in table III. First, we tested the direct effect of independent variables i.e. workplace bullying (WB) on dependent variable i.e. job performance (JP) and Employee engagement 
(EEN). The results showed the negative but significant association of workplace bullying with job performance $(J P)(B=-.38 ; p=.000)$ and Employee engagement $(E E N)(B=0.44 ; p=.000)$. Secondly, the results showed the presence of positive and significant association between workplace bullying and Emotional Exhaustion $(\mathrm{B}=0.39 ; \mathrm{p}=.000)$. Then, we investigated the impact of emotional exhaustion $(\mathrm{EEX})$ on job performance $(\mathrm{JP})(\mathrm{B}=0.59 ; \mathrm{p}=.000)$ and Employee engagement $(\mathrm{EEN})(\mathrm{B}=0.42 ; \mathrm{p}=.000)$ and results found their negative association. Similarly, at fourth step, a negative but insignificant relationship is found between workplace bullying and job performance (JP) $(\mathrm{B}=-.18 ; \mathrm{p}=.000)$ and Employee engagement $(E E N)(B=-.29 ; p=.000)$ in the presence of mediation. These results showed the presence of full mediation as all four conditions of mediation is are fulfilled. Similarly, the model fit values were also within acceptable range proving that hypothesis 2 and hypothesis 4 are accepted.

Table III: Mediation Analysis

\begin{tabular}{|c|c|c|c|c|c|c|c|c|c|}
\hline & & $\mathbf{B}$ & S.E. & C.R. & CMIN & CFI & IFI & RMSEA & RMR \\
\hline \multirow[t]{2}{*}{ Step 1} & Direct Effect of WB on JP & $-.38 * *$ & .046 & -17.68 & 2.26 & 0.90 & 0.89 & 0.07 & 0.06 \\
\hline & Direct Effect of WB on ENN & $-.44 * *$ & 0.59 & -15.26 & 2.71 & 0.89 & 0.91 & 0.06 & 0.05 \\
\hline Step 2 & Direct Effect of WB on EEX & $.39^{* *}$ & 0.42 & -14.21 & 3.23 & 0.94 & 0.90 & 0.06 & 0.07 \\
\hline \multirow[t]{2}{*}{ Step 3} & Direct Effect of EEX on JP & $-.59^{*}$ & 0.36 & -14.02 & 2.99 & 0.95 & 0.83 & 0.05 & 0.03 \\
\hline & Direct Effect of EEX on ENN & $-.42^{*}$ & 0.64 & -16.21 & 3.42 & 0.88 & 0.95 & 0.02 & 0.01 \\
\hline \multirow[t]{2}{*}{ Step 4} & Mediation of EEX btw WB and JP & -.18 & 0.58 & -16.45 & 3.01 & 0.96 & 0.92 & 0.01 & 0.000 \\
\hline & Mediation of EEX btw WB and EEN & -.29 & 0.71 & -15.29 & 2.89 & 0.95 & 0.94 & 0.04 & 0.05 \\
\hline
\end{tabular}

\section{Conclusion}

The overwhelming literature confined to the workplace bullying, job stress, job demands \& emotional exhaustion cause a wide variety of repercussions with respect to job performance and job engagement. Being the most ignored and underestimated phenomenon in Pakistani research context, Pakistani organizations are unable to rule out the unbridled pervasiveness of workplace bullying but simply accept that strain is the customary facet of job. Even though there is the lack of awareness about workplace bullying in developing countries but its repercussions are realized and addressed internationally. Since Pakistan lies in the second layer of the developing countries, therefore the understanding of workplace bullying will take time to trickle down. By following the Hofstede's cultural dimension of collectivism, the span of control believes in resilience and tolerance to workplace bullying. This study stimulates the intervention strategies to create the bullying free workplace environment in Pakistan. As per this study the primary intervention strategy is to instill and create awareness in the work force. At the secondary level the clinical psychologists and industrial psychologists along with managers will get help from this study as the dearth of knowledge exists about this phenomenon. Since lack literacy about bullying may lead to misdiagnosis and false medications .Pakistan has only act 2010 which was revised in 2014 covering both genders regarding harassment. Further vigorous insights are required by Pakistani government to curtail down its effects, which will yield better performance outcomes.Since the results of this study talked about the deleterious effects on organizational health via emotional exhaustion. Being the researchers our study will definitely promote more investigations underlying workplace bullying to lessen its detrimental effects.

\section{Limitations and Future Directions}

This study has definite limitations. The opinion poll is based on the self-reporting since the responses may suffer from bias future research should be based upon the responses from all the three sides like managers, peer group and span of control. Furthermore, cross sectional research may dilute the accuracy of findings the longitudinal study may generate results that are more reliable. This study is a contribution to workplace bullying literature and it offers the new avenues of research for future. This research can be replicated according to the circumstances in different geographical contexts. 


\section{References}

Arenas, A., Giorgi, G., Montani, F., Mancuso, S., Perez, J. F., Mucci, N., \& Arcangeli, G. (2015a). Workplace bullying in a sample of Italian and Spanish employees and its relationship withjob satisfaction, and psychological well-being. Frontiers in Psychology, 6, e1912. https://doi. org/10.3389/fpsyg.2015.01912.

Attell, B. K., Brown, K. K., \& Treiber, L. A. (2017). Workplace bullying, perceived job stressors, and psychological distress: Gender and race differences in the stress process. Social Science Research, 65, 112 , In press.

Bagozzi, R. P., \& Yi, Y. (2012). Specification, evaluation, and interpretation of structural equation models. Journal of the academy of marketing science, 40(1), 8-34.

Bakker, A. B., \& Demerouti, E. (2007). The job demands-resources model: State of the art. Journal of Managerial Psychology, 22(3), 309-328.

Bakker, A. B., Schaufeli, W. B., Leiter, M. P., \& Taris, T. W. (2008). Work engagement: An emerging concept in occupational health psychology. Work \& Stress, 22, 187-200.

Bolton, L. R., Harvey, R. D., Grawitch, M. J., and Barber, L. K. (2012), "Counterproductive work behaviors in response to emotional exhaustion: A moderated meditational approach", Stress and Health, Vol, 28, pp.222-233.

Bowling, N.A. and Beehr, T.A. (2006), "Workplace harassment from the victim's perspective: a theoretical model and meta-analysis", Journal of Applied Psychology, Vol. 91 No. 5, pp. 998-1012.

Crawford, E. R., LePine, J. A., \& Rich, B. L. (2010). Linking job demands and resources to employee engagement and burnout: A theoretical extension and meta-analytic test. American Psychological Association. Retrieved from http://psycnet.apa.org/journals/apl/95/5/834/

D Hooper, J Coughlan, M Mullen - Articles, 2008 - arrow.dit.ie

D’Cruz, P., Paull, M., Omari, M., \& Guneri-Cangarli, B. (2016). Target experiences of workplace bullying: Insights from Australia, India and Turkey. Employee Relations: The International Journal, 38(5), 805-823.

Einarsen, S. (2000). Harassment and bullying at work: A review of the scandinavian approach. Aggression and Violent Behavior, 5, 379-401.

Einarsen, S., Hoel, H., Zapf, D., \& Cooper, C. L. (2011). The concept of bullying and harassment at work: The European tradition. In S. Einarsen, H. Hoel, D. Zapf, \& C. L. Cooper (Eds.), Bullying and harassment in the workplace: Developments in theory, research, and practice (pp. 3-40). Boca Raton: CRC

Einarsen, S., Skogstad, A., Rørvik, E., Lande, A. B., \& Nielsen, M. B. (2016). Climate for conflict management, exposure to workplace bullying and work engagement: A moderated mediation analysis. The International Journal of Human Resource Management, 1-22.

Escartin, J., Zapf, D., Arrieta, C., \& Rodriguez-Carballeira, A. (2011). Workers' perception of workplace bullying: A cross-cultural study. European Journal of Work and Organizational Psychology, 20(2), 178205. https://doi.org/10.1080/13594320903395652.

Giorgi, G. (2012). Workplace bullying in academia creates a negative work environment: An Italian study. Employee Responsibilities \& Rights Journal, 24(4), 261-275. https://doi.org/10.1007/s10672-0129193-7.

Glaso, L., Vie, T. L., Holmdal, G. R., \& Einarsen, S. (2011a). An application of affective events theory to workplace bullying: The role of emotions, trait anxiety, and trait anger. European Psychologist, 16, 198208.

Gorgievski, M. J., \& Hobfoll, S. E. (2008). Work can burn us out or fire us up: Conservation of resources in burnout and engagement. In J. R. B. Halbesleben (Ed.), Handbook of stress and burnout in health care (pp. 7-22). Hauppauge, NY: NOVA Science

Gupta, R. (2017). Impact of workplace bullying on employee and organizational well-being in human services sector. Doctoral Dissertation, University of Jammu, India.

Harrington, D. (2009). Confirmatory factor analysis. Oxford University Press.

Hobfoll, G. H. and Shirom, A. (2001), Handbook of organizational behavior. Marcel Dekker. New York. 
Hobfoll, S. E. (1989). Conservation of resources: A new attempt at conceptualizing stress. American Psychologist, 44(3), 513.

Hobfoll, S. E., \& Shirom, A. (2001). Conservation of resource theory: Applications to stress and management in the workplace. In R. T. Golembiewski (Ed.), Handbook of organizational behavivor (2nd ed.). (pp. 57-80). New York, NY: Marcel Dekker.

Hochschild, A. R. (1983), The managed heart. Berkeley: University of California Press

Hogh, A., Hansen, A. M., Mikkelsen, E. G., \& Persson, R. (2012). Exposure to negative acts at work, psychological stress reactions and physiological stress response. Journal of Psychosomatic Research, 73, 47-52.

Houshmand, M., O’Reilly, J., Robinson, S., \& Wolff, A. (2012). Escaping bullying: The simultaneous impact of individual and unit-level bullying on turnover intentions. Human Relations, 65, 901-918.

Hu, L. T., \& Bentler, P. M. (1999). Cutoff criteria for fit indexes in covariance structure analysis: Conventional criteria versus new alternatives. Structural equation modeling: a multidisciplinary journal, 6(1), 1-55.

Hurley, J., Hutchinson, M., Bradbury, J., \& Browne, G. (2016). Nexus between preventive policy inadequacies, workplace bullying, and mental health: Qualitative findings from the experiences of Australian public sector employees. International Journal of Mental Health Nursing, 25(1), 12-18. https://doi.org/10.1111/inm.12190.

Jackson, D., Clare, J. and Mannix, J. (2002), "Who would want to be a nurse? Violence in the workplace - a factor in recruitment and retention”, Journal of Nursing Management, Vol. 10 No. 1, pp. 13-20.

Jarvis, C. B., MacKenzie, S. B., \& Podsakoff, P. M. (2003). A critical review of construct indicators and measurement model misspecification in marketing and consumer research. Journal of consumer research, 30(2), 199-218.

Kahn, W. A. (1990). Psychological conditions of personal engagement and disengagement at work. Academy of Management Journal, 33(4), 692-724.

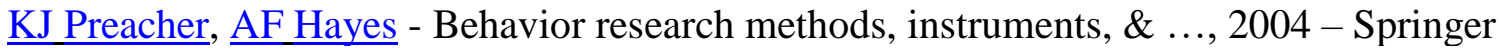

L Hu, PM Bentler - ... equation modeling: a multidisciplinary journal, 1999 - Taylor \& Francis

Macey, W. H., \& Schneider, B. (2008). The meaning of employee engagement. Industrial and Organizational Psychology, 1(1), 3-30.

Maslach, C. and Jackson, S. E. (1984), "Burnout in organizational settings", In S. Oskamp (Ed.), Applied Social Psychology Annual: Applications in Organizational Settings, Thousand Oaks, California: Sage, pp. 133-153.

Maslach, C., Schaufeli, W. B. and Leiter, M. P. (2001), "Job burnout”, Annual Review of Psychology, Vol. 52, pp. 397-422.

May, D. R., Gilson, R. L., \& Harter, L. M. (2004). The psychological conditions of meaningfulness, safety and availability and the engagement of the human spirit at work. Journal of Occupational and Organizational Psychology, 77(1), 11-37.

McMillan, I. (1995), “Losing control”, Nursing Times, Vol. 91 No. 15, pp. 40-43.

Meurs, J. A., \& Perrewe, P. L. (2011). Cognitive activation theory of stress: An integrative theoretical approach to work stress. Journal of Management, 37, 1043-1068.

Mikkelsen, E. G., \& Einarsen, S. (2002). Relationships between exposure to bullying at work and psychological and psychosomatic health complaints: The role of state negative affectivity and generalized self-efficacy. Scandinavian Journal of Psychology, 43, 397-405.

Miner, A. G., Glomb, T. M. and Hulin, C. (2005), "Experience sampling mood and its correlates at work", Journal of Occupational and Organizational Psychology, Vol. 78 No. 2, pp. 171-193.

Nielsen, M. B. and Einarsen, S. (2012), "Outcomes of workplace bullying: a meta-analytic review", Work and Stress, Vol. 26 No. 4, pp. 309-332.

Nielsen, M. B., Matthiesen, S. B., \& Einarsen, S. (2008). Sense of coherence as a protective mechanism among targets of workplace bullying. Journal of Occupational Health Psychology, 13, 128-136.

Park, J.H., \& Ono, M. (2016). Effects of workplace bullying on work engagement and health: The mediating role of job insecurity. The International Journal of Human Resource Management, 1-24. https://doi.org/10.1080/09585192.2016.1155164. 
Parzefall, M.-R., \& Salin, D. M. (2010). Perceptions of and reactions to workplace bullying: A social exchange perspective. Human Relations, 63, 761-780.

Peng, Y. C., Chen, L. J., Chang, C. C., \& Zhuang, W. L. (2016). Workplace bullying and workplace deviance: The mediating effect of emotional exhaustion and the moderating effect of core selfevaluations. Employee Relations, 38(5), 755-769.

Penhaligon, N. L., Louis, W. R., \& Restubog, S. L. D. (2013). Feeling left out? The mediating role of perceived rejection on workgroup mistreatment and affective, behavioral, and organizational outcomes and the moderating role of organizational norms. Journal of Applied Social Psychology, 43, 480-497.

Raman, P., Sambasivan, M. and Kumar, N. (2016), "Counterproductive work behavior among frontline government employees: Role of personality, emotional intelligence, affectivity, emotional labor, and emotional exhaustion", Journal of Work and Organizational Psychology, Vol. 32, pp.25-37.

Refsgaard, J. C., Van der Sluijs, J. P., Brown, J., \& Van der Keur, P. (2006). A framework for dealing with uncertainty due to model structure error. Advances in Water Resources, 29(11), 1586-1597.

Rodriguez-Munoz, A., Baillien, E., De Witte, H., Moreno-Jimenez, B., \& Pastor, J. C. (2009). Crosslagged relationships between workplace bullying, job satisfaction and engagement: Two longitudinal studies. Work \& Stress, 23, 225-243.

Rodriguez-Munoz, A., Moreno-Jimenez, B., Sanz Vergel, A. I., \& Garrosa Hernandez, E. (2010). Posttraumatic symptoms among victims of workplace bullying: Exploring gender differences and shattered assumptions. Journal of Applied Social Psychology, 40, 2616-2635.

Schaufeli, W. B., \& Bakker, A. (2003). Test manual for the Utrecht work engagement scale. The Netherlands: Utrecht University

Schaufeli, W. B., Salanova, M., González-Romá, V., \& Bakker, A. B. (2002). The measurement of engagement and burnout: A two sample confirmatory factor analytic approach. Journal of Happiness Studies, 3(1), 71-92.

Spector, P. E., and Fox, S. (2005), "the stressor-emotion model of counterproductive work behavior (CWB)". In S. Fox \& P. E. Spector (Eds.), Counterproductive work behavior: Investigations of actors and targets. Washington, DC: American Psychological Association, pp, 151-174.

Tabachnick, B. G., \& Fidell, L. S. (1996). Using multivariate statistics . Northridge. Cal.: Harper Collins. Tabachnick, B. G., \& Fidell, L. S. (2007). Using multivariate statistics. Allyn \& Bacon/Pearson Education.

Trépanier, S. G., Fernet, C. and Austin, S. (2013), "Workplace bullying and psychological health at work: The mediating role of satisfaction of needs for autonomy, competence and relatedness", Work and Stress, Vol. 27 No. 2, pp. 123-140.

Tuckey, M. R., \& Neall, A. M. (2014). Workplace bullying erodes job and personal resources: Betweenand within-person perspectives. Journal of Occupational Health Psychology, 19(4), 413.

Ursin, H., \& Eriksen, H. R. (2004). The cognitive activation theory of stress. Psychoneuroendocrinology, 29, 567-592.

Vie, T. L., Glaso, L., \& Einarsen, S. (2011). Health outcomes and self-labeling as a victim of workplace bullying. Journal of Psychosomatic Research, 70(1), 37-43. https://doi.org/10.1016/j. jpsychores.2010.06.007.

Vie, T. L., GlasO, L., \& Einarsen, S. (2012). How does it feel? Workplace bullying, emotions and musculoskeletal complaints. Scandinavian Journal of Psychology, 53, 165-173.

Weiss, H. M., \& Cropanzano, R. (1996). Affective events theory: A theoretical discussion of the structure, causes, and consequences of affective experiences at work. Research in Organizational Behavior, 18, 174.

Witt, L. A., Andrews, M. C. and Carlson, D. S. (2004), “When conscientiousness isn't enough: Emotional exhaustion and performance among call center customer service representatives", Journal of Management, Vol. 30 No. 1, pp. 149-160.

Wright, T. A. and Cropanzano, R. (2000), "Psychological well-being and job satisfaction as predictors of job performance", Journal of Occupational Health Psychology, Vol. 5 No. 1, pp. 84-94.

Xu, A. J., Loi, R., \& Lam, L. W. (2015). The bad boss takes it all: How abusive supervision and leadermember exchange interact to influence employee silence. The Leadership Quarterly, 26(5), 763-774. 